Revista Perspectivas Online: Exatas \& Engenharias Julho de 2017, Vol.7, n 18, p. 22-31

ISSN: 2236-885X (Online)

DOI: $10.25242 / 885 \times 71820171192$

\title{
IMPLEMENTAÇÃO DE UM MODELO DE SUPPLY CHAIN MANAGEMENT NA FÁBRICA DE VASSOURAS ECOLÓGICAS TAMARINDO
}

\author{
Alice de Assis Abreu ${ }^{1}$, Yasmin de Almeida Barreto ${ }^{2}$, Maraisa Silva Martins ${ }^{2}$, Bárbara \\ Mercadante de Resende ${ }^{1}$, Leonardo da Silva Ribeiro ${ }^{3 *}$
}

\section{RESUMO}

ABREU, A.A.; BARRETO, Y.A.; MARTINS, M.S.; RESENDE, B.M.; RIBEIRO, L.S. Implementação de um modelo de Supply Chain Management na Fábrica de Vassouras Ecológicas Tamarindo. Perspectivas Online: Exatas \& Engenharias, v. 7, n.18, p.22-31, 2017.

Compete ao Suplly Chain Management (SCM) a gestão eficaz das atividades onde é dentro do processo que as informações sobre os integrantes da mesma são utilizadas para desenvolver melhorias no sistema logístico. O referido trabalho tem como propósito realizar um estudo para a implementação de um modelo de gerenciamento da cadeia de suprimentos, e observar o processo logístico da fábrica de vassouras ecológicas instalada na Comunidade Tamarindo em Campos dos Goytacazes desde o fornecedor do fornecedor até o cliente final, desenvolvendo ferramentas especificas para a melhoria dos estoques, armazenagem, produção, distribuição e vendas. Para a realização desse trabalho irá se desenvolver um estudo exploratório, envolvendo pesquisa bibliográfica, documental e qualitativa com o propósito de aprofundar os conhecimentos sobre o tema proposto, sendo o mesmo direcionado para o estudo de caso.

Palavras-chave: Supply Chain Management, Logística, Produção. 


\begin{abstract}
Suplly Chain Management (SCM) is responsible for the effective management of the activities within the process and that the information about the members of the process is used to develop improvements in the logistics system. The aim of the project is to carry out a study of a supply chain management model and to observe the logistic process of the ecological

Community in Campos dos Goytacazes from the supplier supplier to the final customer. Storage, production, distribution and sales. For a study, it is an exploratory study, involving bibliographical, documentary and qualitative research with the purpose of deepening the knowledge about the proposed theme, being the same one directed to the case study.
\end{abstract} broom plant installed in the Tamarindo

Keywords: Supply Chain Management, Logistics, Production

${ }^{1}$ Institutos Superiores de Ensino do CENSA - ISECENSA - Acadêmico do Curso de Graduação em Engenharia de Produção - Rua Salvador Correa, 139, Centro, Campos dos Goytacazes, RJ, CEP: 28035-310, Brasil;

${ }^{2}$ Institutos Superiores de Ensino do CENSA - ISECENSA - Acadêmico do Curso de Graduação em Administração Rua Salvador Correa, 139, Centro, Campos dos Goytacazes, RJ, CEP: 28035-310, Brasil;

${ }^{3}$ Institutos Superiores de Ensino do CENSA - ISECENSA - Laboratório de Gestão Estratética - Rua Salvador Correa, 139, Centro, Campos dos Goytacazes, RJ, CEP: 28035-310, Brasil;

(*)e-mail: leoribeiro@globo.com

Data de chegada: 20/05/2017 Aceito para publicação: 28/07/2017 


\section{INTRODUÇÃO}

As empresas de uma maneira geral, independentemente do seguimento, vivem em seus cenários sejam locais, nacionais ou internacionais cada vez mais uma competitividade intensa, levando a busca constante por vantagens competitivas para manter-se no mercado. Diante disso, as organizações começaram a dar preferências aos aspectos que envolvem a logística empresarial e integrada, sendo essa uma área de fundamental importância dentro dos ambientes empresariais, uma vez que a logística tem a finalidade de otimizar recursos, e dessa forma aumentar a eficiência.

Tem-se então o processo de reciclagem, que além de preservar o meio ambiente também gera riquezas, os materiais mais reciclados são o plástico, vidro, alumínio e papel (PRINGLE; BARKER, 2000). A reciclagem contribui para a diminuição significativa da poluição do solo, da água e do ar. Muitas indústrias estão reciclando materiais como uma forma de reduzir os custos de produção.

As empresas, a partir desse contexto, começam a realizar a integração da reciclagem com a logística reversa, que juntamente com a logística de abastecimento, logística interna e logística de distribuição formam a cadeia de suprimentos, e dessa forma o objetivo do gerenciamento da cadeia de suprimentos passa a ser de agregar valor à cadeia buscando maior lucratividade ao negócio, ou seja, minimizando custos e maximizando receitas.

Segundo Martins e Laugeni (2000), todas as atividades desenvolvidas por uma empresa visando atender seus objetivos de curto, médio e longo prazo se inter-relacionam, na maioria das vezes de forma complexa. Diante disso, como tais atividades transformam insumos e matérias-primas em produtos acabados e/ou serviços, demandam recursos que, por sua vez devem agregar valor ao produto final, isso constitui um dos principais objetivos da Administração da Produção/Operações na gestão empresarial.

Segundo Poirier \& Reiter (1997), uma cadeia de suprimentos (supply chain) é um sistema por meio do qual empresas e organizações entregam produtos e serviços a seus consumidores, em uma rede de organizações interligadas.

A cadeia engloba todos os estágios envolvidos, direta ou indiretamente no atendimento de um pedido de um cliente e não inclui apenas fabricantes e fornecedores, mas também transportadoras, depósitos, varejistas e os próprios clientes (CHOPRA; MEINDL, 2004).

Compreender como ocorre o supply chain management é de suma importância, pois é através desse processo que informações sobre clientes, fornecedores, fornecedores dos fornecedores, manuseio, movimentação e armazenagem de materiais são utilizadas para melhorias contínuas no sistema logístico. Nesse sentido, o ambiente de negócios exige das empresas três fatores básicos de acordo com Ballou (2006): maior agilidade, melhores performances e a constante procura por redução de custos.

Esse projeto tem como propósito realizar um estudo sobre a integração do processo do gerenciamento da cadeia de suprimentos, verificando a integração do processo logístico para criar um modelo de gerenciamento para a fábrica de vassouras ecológicas Tamarindo desde o fornecedor do fornecedor até o cliente final. 


\section{METODOLOGIA}

Este projeto caracteriza-se como uma pesquisa exploratória descritiva de natureza quali-quantitativa, visando à análise do sistema de planejamento e controle produtivo, gestão de produção e formação do preço de venda dos produtos estudados. Pois envolvem o levantamento bibliográfico e entrevistas com pessoas que tiveram experiências práticas com o problema pesquisado.

Este trabalho coloca-se na categoria de pesquisa exploratória, pois apresenta caráter avaliativo. Segundo Gil (2005), a pesquisa exploratória objetiva, em geral, "provocar o esclarecimento de uma situação para a tomada de consciência". Segundo o mesmo autor, "um estudo exploratório ocupa o primeiro de cinco níveis diferentes e sucessivos, sendo indicado quando existe pouco conhecimento sobre o fenômeno".

Esta pesquisa será estruturada em duas atividades: uma teórica, de fundamentação conceitual, e outra prática, de coleta de dados, as quais se desenvolveram simultaneamente, uma auxiliando a outra, no sentido de atingir os objetivos propostos. Cabe ressaltar que a pesquisa terá início com o acompanhamento do processo produtivo, através de visitas in loco na Fábrica ecológica de Vassouras na comunidade Tamarindo, por motivos de intencionalidade e acessibilidade. Uma pesquisa Intencional pelo fato de ter a necessidade de um novo modelo de gestão através de estudo na fábrica e por acessibilidade com relação aos dados serem disponíveis em tempo hábil para realização da pesquisa.

\section{REFORMULAÇÃO DA CADEIA DA FÁBRICA}

O sistema da Cadeia de Suprimentos da Fábrica foi restruturado em 3 partes: Produção, Novo Produto e Indicadores de Desempenho. A primeira reformulação veio com importância máxima de cadeia de suprimentos que é a otimização da produção onde a partir de levantamentos com simulação de tempo e produtividade dos equipamentos e colaboradores, a fabricação da vassoura ecológica, desde a lavagem das garrafas até o produto final, foi defina com13 processos, levando em conta reposição de garrafas, confecção de grampos e outros detalhes necessários para a produção, sendo eles:

$1^{\circ}$ : Lavagem de 10 garrafas tem uma duração entre 20 e 30 minutos;

$2^{\circ}$ : Corte das 10 garrafas tem uma duração de 10 minutos e 47 segundos, sendo 5 segundos em cada garrafa;

$3^{\circ}$ : Desfio tem um tempo médio de 30 segundos para cada garrafa;

$4^{\circ}$ : Reposição de garrafas para o desfio leva em média 40 segundos cada uma;

$5^{\circ}$ : Passar para a grade tem uma duração de 7 minutos e 50 segundos;

$6^{\circ}$ : Forno/Secagem tem uma duração de 1 hora;

$7^{\circ}$ : Logo após a secagem é feito um resfriamento do material que tem um tempo de duração de 30 minutos;

$8^{\circ}$ : A retirada da grade e o corte têm uma duração de 1 hora e 20 minutos;

$9^{\circ}$ : Confecção de 49 grampos tem uma duração de 3 minutos e 50 segundos;

$10^{\circ}$ : Colocar as cerdas, 8 cerdas em cada grampo, nos 49 grampos tem um tempo de 30 minutos; 
11: Colocar os grampos com as cerdas na base tem uma duração de 1 hora e 45 minutos;

$12^{\circ}$ : Corte final tem um tempo de duração de 40 segundos;

13: Colocar o cabo na base tem uma duração de 1 dia.

A segunda parte vem com o advento de uma nova base para a vassoura deixando ela $25 \%$ mais eficiente do que a anterior como mostra a Figura 1 onde novos furos foram inseridos para inserção das cerdas que ganharam também um aspecto mais fino para uma maior flexibilidade de uso.

Esta inovação gerou vendas em maior quantidade para pessoas físicas e jurídicas, a exemplo de uma grande multinacional que se encontra estabelecida no Porto do Açu, no município de São Joao da Barra, RJ.

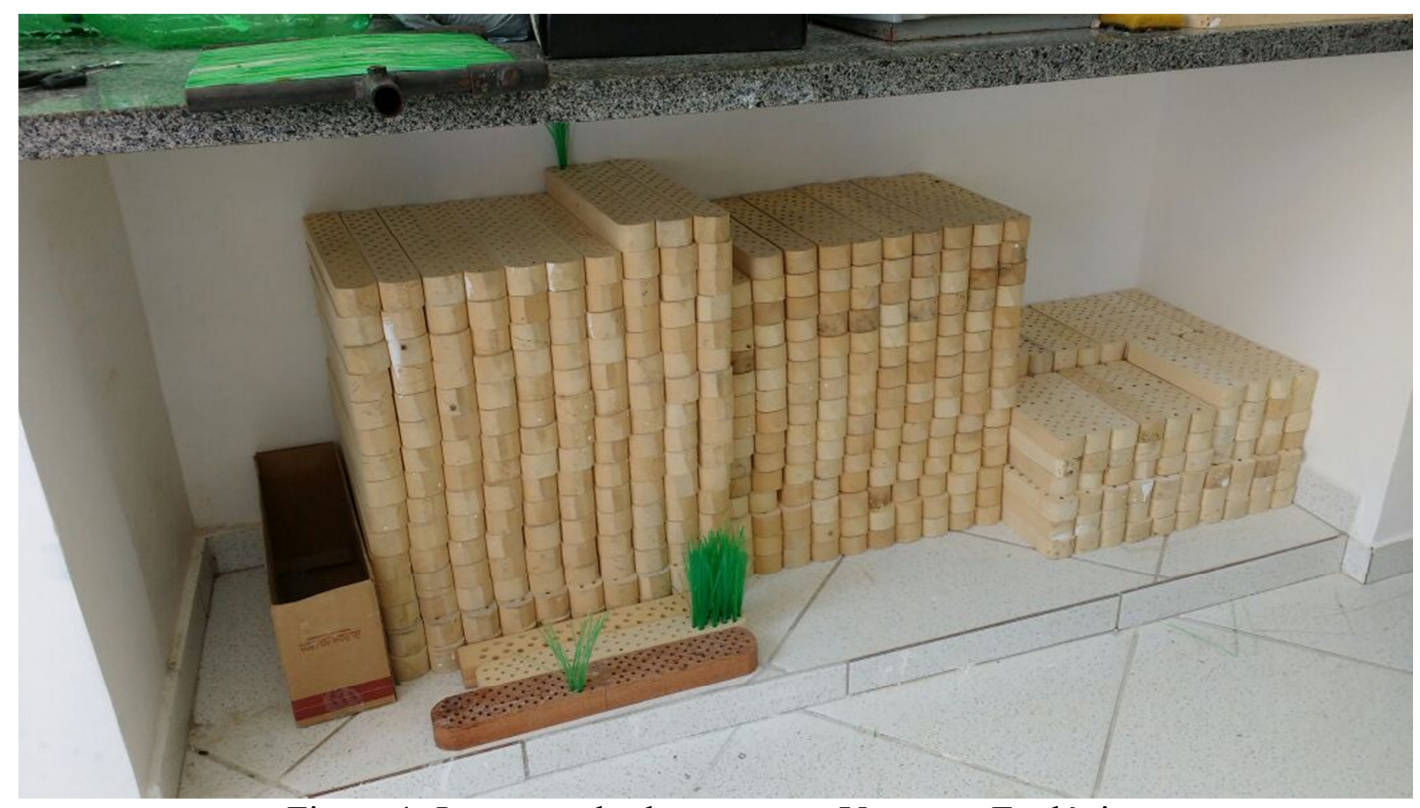

Figura 1: Inovação das bases para a Vassoura Ecológica

Fonte: Própria (2016)

O controle da produção ficou mais efetivo pois o gerenciamento da produção com o novo tempo criou uma percepção entre os colaboradores da Fábrica que conseguiram esquematizar trabalhando no estoque de segurança, mantendo assim, uma quantidade mais precisa para ser produzido de acordo com as demandas, evitando assim novos desperdícios de todos os materiais insumos, semiacabados e acabados.

Conforme mostra a Figura 2, toda a área da fábrica também ganhou sinalização e normativas de segurança, saúde e higiene criando um ambiente mais limpo em todo o processo de produção. 


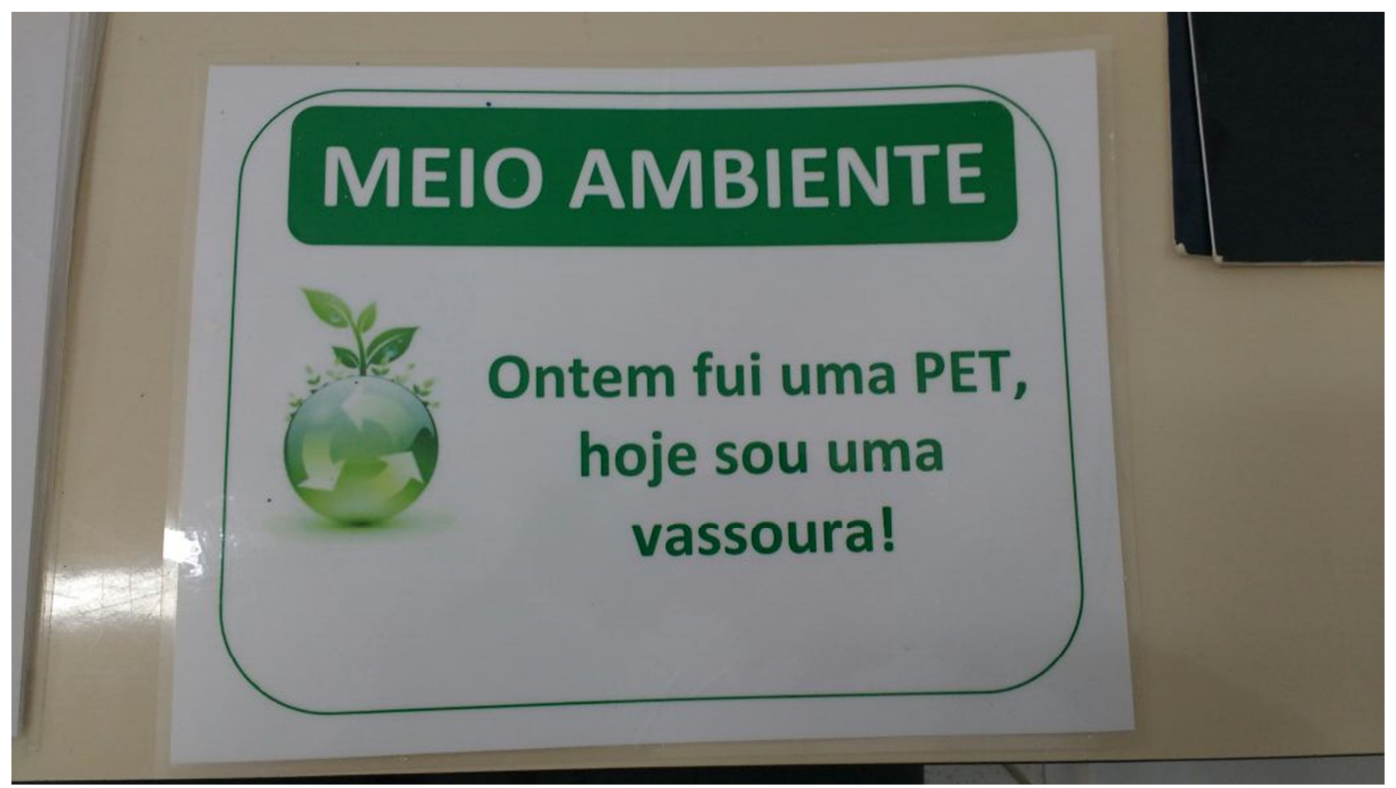

Figura 1: Uma das sinalizações da Fábrica

Fonte: Própria (2016)

Desenvolver um indicador de desempenho que considere todos os componentes da cadeia de suprimentos em termos de estoque, nível de atendimento e eficiência. (Carvalho, 2005)

Por isso, a terceira parte da reformulação está na prática dos indicadores de desempenho que ajudarão toda a Cadeia de Suprimentos a compreender os resultados das ações aplicadas em várias áreas como mostra as Matrizes.

\section{Matriz de Avaliação}

\section{Indicadores Sociais}

\begin{tabular}{|c|c|c|c|c|c|c|}
\hline $\begin{array}{c}\text { Indicadores do } \\
\text { PRÊMIO }\end{array}$ & Público (1) & $\begin{array}{c}\text { Objetivos } \\
\text { Específicos do } \\
\text { projeto (2) }\end{array}$ & $\begin{array}{l}\text { Ações do projeto } \\
\text { (3) }\end{array}$ & $\begin{array}{l}\text { Fontes de } \\
\text { Informação } \\
\text { (4) }\end{array}$ & $\begin{array}{l}\text { Meios de } \\
\text { verificaçãao } \\
\text { (5) }\end{array}$ & $\begin{array}{l}\text { Respons } \\
\text { áveis (6) }\end{array}$ \\
\hline $\begin{array}{l}\text { 1. Empoderamento } \\
\text { dos beneficiários }\end{array}$ & Beneficiários & $\begin{array}{l}\text { Aumento da } \\
\text { autoestima e da renda } \\
\text { dos moradores }\end{array}$ & $\begin{array}{c}\text { Geração de } \\
\text { oportunidades de } \\
\text { trabalho e reforma } \\
\text { das casas dos } \\
\text { moradores }\end{array}$ & $\begin{array}{l}\text { Relatórios com } \\
\text { o número de } \\
\text { moradores } \\
\text { trabalhadores e } \\
\text { a produção } \\
\text { mensal }\end{array}$ & $\begin{array}{c}\text { Relatório } \\
\text { mensal }\end{array}$ & $\begin{array}{l}\text { EJr } \\
\text { Midas }\end{array}$ \\
\hline $\begin{array}{l}\text { 2. Melhoria na } \\
\text { qualidade de vida } \\
\text { (trabalho, saúde e } \\
\text { educação) }\end{array}$ & Beneficiários & $\begin{array}{l}\text { Geração de } \\
\text { oportunidades de } \\
\text { trabalho }\end{array}$ & $\begin{array}{l}\text { Melhoria da } \\
\text { fábrica-escola de } \\
\text { vassouras } \\
\text { ecológicas na } \\
\text { comunidade }\end{array}$ & $\begin{array}{l}\text { Relatórios com } \\
\text { o número de } \\
\text { moradores } \\
\text { trabalhadores e } \\
\text { a produção } \\
\text { mensal }\end{array}$ & $\begin{array}{c}\text { Relatório } \\
\text { mensal }\end{array}$ & $\begin{array}{l}\text { EJr } \\
\text { Midas }\end{array}$ \\
\hline $\begin{array}{l}\text { 3. Novas parcerias } \\
\text { estratégicas que } \\
\text { não envolveram } \\
\text { aporte financeiro }\end{array}$ & Beneficiários & $\begin{array}{l}\text { Estreitar ainda mais a } \\
\text { parceria com } \\
\text { CENSA, ISECENSA, } \\
\text { comunidade e } \\
\text { vizinhança na coleta } \\
\text { das garrafas PET }\end{array}$ & $\begin{array}{c}\text { Novas campanhas } \\
\text { de coleta seletiva } \\
\text { de garrafas PET } \\
\text { no CENSA, no } \\
\text { ISECENSA, na } \\
\text { comunidade e na } \\
\text { vizinhança }\end{array}$ & $\begin{array}{l}\text { Número de } \\
\text { parceiros no } \\
\text { processo de } \\
\text { coleta seletiva } \\
\text { / convênios }\end{array}$ & $\begin{array}{l}\text { Arquivo de } \\
\text { Convênios }\end{array}$ & $\begin{array}{l}\text { EJr } \\
\text { Midas }\end{array}$ \\
\hline
\end{tabular}




\begin{tabular}{|c|c|c|c|c|c|c|}
\hline $\begin{array}{l}\text { 4. Ampliação das } \\
\text { competências no } \\
\text { gerenciamento da } \\
\text { organização (do } \\
\text { negócio) - } \\
\text { Dimensão } \\
\text { Empreendedora }\end{array}$ & Beneficiários & $\begin{array}{l}\text { Cursos para os alunos } \\
\text { da EJr, que } \\
\text { repassarão, por meio } \\
\text { de práticas na } \\
\text { fábrica-escola, para } \\
\text { os moradores } \\
\text { trabalhadores }\end{array}$ & $\begin{array}{c}\text { Cursos / } \\
\text { Treinamento em: } \\
\text { Marketing e } \\
\text { Planejamento } \\
\text { Estratégico; } \\
\text { Qualidade, } \\
\text { Inovação } \\
\text { Tecnológica, } \\
\text { Gestão Ambiental } \\
\text { e Gerência da } \\
\text { Produção }\end{array}$ & $\begin{array}{l}\text { Relatórios } \\
\text { trimestrais } \\
\text { com o número } \\
\text { de estudantes e } \\
\text { moradores } \\
\text { trabalhadores } \\
\text { treinados }\end{array}$ & $\begin{array}{l}\text { Relatório } \\
\text { Trimestral }\end{array}$ & $\begin{array}{l}\text { EJr } \\
\text { Midas }\end{array}$ \\
\hline $\begin{array}{l}\text { 5. Aprimoramento } \\
\text { das habilidades } \\
\text { profissionais }\end{array}$ & Beneficiários & $\begin{array}{l}\text { Treinamento dos } \\
\text { moradores } \\
\text { trabalhadores para a } \\
\text { operacionalização } \\
\text { dos equipamentos da } \\
\text { fábrica-escola }\end{array}$ & $\begin{array}{l}\text { Orientação dos } \\
\text { moradores } \\
\text { trabalhadores } \\
\text { pelos alunos da } \\
\text { EJr }\end{array}$ & $\begin{array}{c}\text { Relatórios } \\
\text { trimestrais } \\
\text { com o número } \\
\text { de estudantes e } \\
\text { moradores } \\
\text { trabalhadores } \\
\text { treinados }\end{array}$ & $\begin{array}{l}\text { Relatório } \\
\text { Trimestral }\end{array}$ & $\begin{array}{l}\text { EJr } \\
\text { Midas }\end{array}$ \\
\hline $\begin{array}{l}\text { 6. Beneficiários do } \\
\text { projeto atuam na } \\
\text { capacitação de } \\
\text { outros participantes } \\
\text { do projeto }\end{array}$ & Beneficiários & $\begin{array}{l}\text { Os próprios mais } \\
\text { antigos moradores } \\
\text { trabalhadores treinam } \\
\text { os novos moradores } \\
\text { trabalhadores }\end{array}$ & $\begin{array}{l}\text { Orientação dos } \\
\text { moradores } \\
\text { trabalhadores } \\
\text { pelos alunos da } \\
\text { EJr }\end{array}$ & $\begin{array}{l}\text { Relatórios } \\
\text { trimestrais } \\
\text { com o número } \\
\text { de estudantes e } \\
\text { moradores } \\
\text { trabalhadores } \\
\text { treinados }\end{array}$ & $\begin{array}{l}\text { Relatório } \\
\text { Trimestral }\end{array}$ & $\begin{array}{c}\text { EJr } \\
\text { Midas }\end{array}$ \\
\hline $\begin{array}{l}\text { 7. Melhores } \\
\text { condições de } \\
\text { segurança e } \\
\text { salubridade }\end{array}$ & $\begin{array}{l}\text { Beneficiários/ } \\
\text { iniciativas }\end{array}$ & $\begin{array}{l}\text { Estímulo ao uso de } \\
\text { uniformes e } \\
\text { equipamentos de } \\
\text { proteção individual } \\
\text { pelos os moradores } \\
\text { trabalhadores }\end{array}$ & $\begin{array}{l}\text { Serão comprados } \\
\text { uniformes e } \\
\text { equipamentos de } \\
\text { proteção } \\
\text { individual para os } \\
\text { moradores } \\
\text { trabalhadores }\end{array}$ & $\begin{array}{c}\text { Relatórios } \\
\text { trimestrais } \\
\text { com o número } \\
\text { de acidentes de } \\
\text { trabalho } \\
\text { ocorridos na } \\
\text { fábrica-escola }\end{array}$ & $\begin{array}{l}\text { Relatório } \\
\text { Trimestral }\end{array}$ & $\begin{array}{c}\text { EJr } \\
\text { Midas }\end{array}$ \\
\hline $\begin{array}{l}\text { 8. Apropriação das } \\
\text { práticas e } \\
\text { tecnologias por } \\
\text { parte da } \\
\text { comunidade }\end{array}$ & $\begin{array}{l}\text { Beneficiários/ } \\
\text { comunidade }\end{array}$ & $\begin{array}{c}\text { Os moradores } \\
\text { trabalhadores deverão } \\
\text { estar aptos a fazerem } \\
\text { a coleta seletiva do } \\
\text { material reciclado e a } \\
\text { produzirem as } \\
\text { vassouras ecológicas }\end{array}$ & $\begin{array}{l}\text { Orientação dos } \\
\text { moradores } \\
\text { trabalhadores } \\
\text { pelos alunos da } \\
\text { EJr }\end{array}$ & $\begin{array}{l}\text { Relatórios } \\
\text { trimestrais } \\
\text { com o número } \\
\text { de estudantes e } \\
\text { moradores } \\
\text { trabalhadores } \\
\text { treinados }\end{array}$ & $\begin{array}{l}\text { Relatório } \\
\text { Trimestral }\end{array}$ & $\begin{array}{l}\text { EJr } \\
\text { Midas }\end{array}$ \\
\hline $\begin{array}{l}\text { 9. Contribuição do } \\
\text { projeto para o } \\
\text { aprimoramento das } \\
\text { práticas na } \\
\text { universidade }\end{array}$ & Universidade & $\begin{array}{l}\text { Promoção da } \\
\text { interdisciplinaridade } \\
\text { do conhecimento na } \\
\text { prática em um caso } \\
\text { real e promoção do } \\
\text { trabalho voluntário e } \\
\text { da responsabilidade } \\
\text { social e ambiental }\end{array}$ & $\begin{array}{c}\text { Cursos / } \\
\text { Treinamento em: } \\
\text { Marketing e } \\
\text { Planejamento } \\
\text { Estratégico; } \\
\text { Qualidade, } \\
\text { Inovação } \\
\text { Tecnológica, } \\
\text { Gestão Ambiental } \\
\text { e Gerência da } \\
\text { Produção }\end{array}$ & $\begin{array}{l}\text { Relatórios } \\
\text { trimestrais } \\
\text { com o número } \\
\text { de estudantes } \\
\text { treinados }\end{array}$ & $\begin{array}{l}\text { Relatório } \\
\text { Trimestral }\end{array}$ & $\begin{array}{l}\text { EJr } \\
\text { Midas }\end{array}$ \\
\hline $\begin{array}{l}\text { 10. Grau de } \\
\text { comprometimento } \\
\text { da universidade } \\
\text { com o projeto }\end{array}$ & Universidades & $\begin{array}{c}\text { A Universidade } \\
\text { desenvolver novos } \\
\text { projetos simultâneos } \\
\text { em diversas áreas e } \\
\text { alugou uma casa para } \\
\text { o desenvolvimento } \\
\text { das atividades }\end{array}$ & $\begin{array}{l}\text { Aluguel da casa e } \\
\text { reforma para o } \\
\text { desenvolvimento } \\
\text { das atividades do } \\
\text { projeto }\end{array}$ & $\begin{array}{c}\text { Relatório } \\
\text { mensal com o } \\
\text { investimento } \\
\text { do ISECENSA } \\
\text { no projeto }\end{array}$ & $\begin{array}{c}\text { Relatório } \\
\text { Mensal }\end{array}$ & $\begin{array}{c}\text { Coordena } \\
\text { dor do } \\
\text { Projeto }\end{array}$ \\
\hline $\begin{array}{l}\text { 11. Envolvimento } \\
\text { em outras } \\
\text { iniciativas sociais }\end{array}$ & Universitários & $\begin{array}{l}\text { Desde sua fundação, } \\
\text { há cerca de } 10 \text { anos, o } \\
\text { ISECENSA } \\
\text { desenvolve projetos } \\
\text { sociais. Criar novos. }\end{array}$ & $\begin{array}{c}\text { São exemplos de } \\
\text { projetos já } \\
\text { desenvolvidos } \\
\text { pelo ISECENSA: } \\
\text { Asilo do Carmo e } \\
\text { Desvendando Rio } \\
\text { Preto }\end{array}$ & $\begin{array}{l}\text { Relatórios de } \\
\text { outros projetos } \\
\text { sociais }\end{array}$ & $\begin{array}{l}\text { Relatórios } \\
\text { parciais e } \\
\text { final de } \\
\text { outros } \\
\text { projetos }\end{array}$ & $\begin{array}{c}\text { Coordena } \\
\text { dor do } \\
\text { Projeto }\end{array}$ \\
\hline $\begin{array}{l}\text { 12. Capacitação } \\
\text { para o trabalho em }\end{array}$ & Universitários & $\begin{array}{c}\text { Semestralmente são } \\
\text { desenvolvidos }\end{array}$ & $\begin{array}{l}\text { Anualmente são } \\
\text { realizadas }\end{array}$ & $\begin{array}{c}\text { Programação } \\
\text { oficial das }\end{array}$ & $\begin{array}{l}\text { Folders e } \\
\text { outros }\end{array}$ & $\begin{array}{c}\text { Coordena } \\
\text { dor do }\end{array}$ \\
\hline
\end{tabular}




\begin{tabular}{|c|c|c|c|c|c|c|}
\hline projetos sociais & & $\begin{array}{l}\text { palestras e cursos na } \\
\text { área de } \\
\text { responsabilidade } \\
\text { social }\end{array}$ & $\begin{array}{l}\text { palestras, visitas } \\
\text { técnicas, Jornadas } \\
\text { Científicas e o } \\
\text { CICC - Congresso } \\
\text { Internacional do } \\
\text { Conhecimento } \\
\text { Científico, onde } \\
\text { palestrantes da } \\
\text { área de } \\
\text { responsabilidade } \\
\text { socioambiental } \\
\text { são convidados }\end{array}$ & $\begin{array}{c}\text { Jornadas } \\
\text { Científicas e } \\
\text { dos CICC e } \\
\text { registros de } \\
\text { palestras e } \\
\text { visitas técnicas }\end{array}$ & registros & Projeto \\
\hline $\begin{array}{l}\text { 13. Construção da } \\
\text { identidade } \\
\text { profissional: } \\
\text { influência do } \\
\text { projeto na } \\
\text { formação do } \\
\text { universitário } \\
\text { enquanto } \\
\text { profissional }\end{array}$ & Universitários & $\begin{array}{l}\text { O trabalho } \\
\text { voluntário, a } \\
\text { responsabilidade } \\
\text { social e ambiental, } \\
\text { bem como a ética e a } \\
\text { religiosidade são } \\
\text { elementos básicos da } \\
\text { identidade do } \\
\text { profissional formado } \\
\text { no ISECENSA }\end{array}$ & $\begin{array}{c}\text { As disciplinas são } \\
\text { obrigatórias como: } \\
\text { Ética Cristã e O } \\
\text { Homem e o } \\
\text { Fenômeno } \\
\text { Religioso em } \\
\text { todos os cursos. } \\
\text { São apoiados, por } \\
\text { meio de Edital de } \\
\text { Iniciação } \\
\text { Científica, os } \\
\text { projetos de } \\
\text { responsabilidade } \\
\text { social }\end{array}$ & $\begin{array}{c}\text { Matriz } \\
\text { Curricular dos } \\
\text { cursos, Edital } \\
\text { de Iniciação } \\
\text { Científica e } \\
\text { Relatórios } \\
\text { Finais e } \\
\text { Parciais das } \\
\text { Bolsas de } \\
\text { Iniciação } \\
\text { Científica }\end{array}$ & $\begin{array}{c}\text { Projeto } \\
\text { Pedagógico } \\
\text { dos Cursos }\end{array}$ & $\begin{array}{c}\text { Coordena } \\
\text { dor do } \\
\text { Projeto }\end{array}$ \\
\hline
\end{tabular}

\section{Indicadores Econômicos}

\begin{tabular}{|c|c|c|c|c|c|c|}
\hline $\begin{array}{c}\text { Indicadores do } \\
\text { PRÊMIO }\end{array}$ & Público (1) & $\begin{array}{c}\text { Objetivos } \\
\text { Específicos do } \\
\text { projeto (2) }\end{array}$ & $\begin{array}{c}\text { Ações do projeto } \\
\text { (3) }\end{array}$ & $\begin{array}{c}\text { Fontes de } \\
\text { Informação (4) }\end{array}$ & $\begin{array}{c}\text { Meios de } \\
\text { verificação } \\
\text { (5) }\end{array}$ & $\begin{array}{c}\text { Responsáveis } \\
\text { (6) }\end{array}$ \\
\hline $\begin{array}{l}\text { 14. Incremento } \\
\text { de renda }\end{array}$ & Beneficiários & $\begin{array}{c}\text { Aumentar a } \\
\text { renda com a } \\
\text { venda das } \\
\text { vassouras } \\
\text { ecológicas }\end{array}$ & $\begin{array}{c}\text { Implantação da } \\
\text { fábrica-escola de } \\
\text { vassouras } \\
\text { ecológicas na } \\
\text { comunidade }\end{array}$ & $\begin{array}{l}\text { Relatórios com o } \\
\text { número de } \\
\text { moradores } \\
\text { trabalhadores, a } \\
\text { produção mensal e } \\
\text { a renda obtida } \\
\text { com a venda das } \\
\text { vassouras }\end{array}$ & $\begin{array}{c}\text { Relatório } \\
\text { Mensal }\end{array}$ & EJr Midas \\
\hline $\begin{array}{l}\text { 15. Mudanças } \\
\text { de hábitos - } \\
\text { consumo de } \\
\text { produtos fruto } \\
\text { das atividades } \\
\text { do projeto }\end{array}$ & $\begin{array}{c}\text { Beneficiários/ } \\
\text { comunidade }\end{array}$ & $\begin{array}{l}\text { A diminuição da } \\
\text { ociosidade das } \\
\text { mulheres da } \\
\text { comunidade e a } \\
\text { utilização das } \\
\text { próprias } \\
\text { vassouras na } \\
\text { limpeza das casas } \\
\text { e comunidade }\end{array}$ & $\begin{array}{c}\text { Geração de } \\
\text { oportunidades de } \\
\text { trabalho e reforma } \\
\text { das casas dos } \\
\text { moradores }\end{array}$ & $\begin{array}{l}\text { Relatórios com o } \\
\text { número de } \\
\text { moradores } \\
\text { trabalhadores, a } \\
\text { produção mensal e } \\
\text { a renda obtida } \\
\text { com a venda das } \\
\text { vassouras }\end{array}$ & $\begin{array}{c}\text { Relatório } \\
\text { Mensal }\end{array}$ & EJr Midas \\
\hline $\begin{array}{c}\text { 16. Acesso a } \\
\text { financiamentos } \\
\text { (governamentais } \\
\text { ou não) }\end{array}$ & $\begin{array}{c}\text { Beneficiários/ } \\
\text { iniciativas }\end{array}$ & $\begin{array}{c}\text { Ainda não está } \\
\text { previsto no } \\
\text { projeto para } 2017\end{array}$ & $\begin{array}{c}\text { Não previsto para } \\
2017\end{array}$ & $\begin{array}{c}\text { Não previsto para } \\
2017\end{array}$ & & \\
\hline $\begin{array}{c}17 . \\
\text { Concretização } \\
\text { de novas } \\
\text { oportunidades } \\
\text { de negócio }\end{array}$ & $\begin{array}{c}\text { Beneficiários/ } \\
\text { iniciativas }\end{array}$ & $\begin{array}{c}\text { Serão } \\
\text { desenvolvidos } \\
\text { novos produtos a } \\
\text { partir de } \\
\text { materiais a serem } \\
\text { reciclados }\end{array}$ & $\begin{array}{c}\text { Com o } \\
\text { treinamento em } \\
\text { Engenharia do } \\
\text { Produto e } \\
\text { Inovação } \\
\text { Tecnológica, } \\
\text { espera-se } \\
\text { desenvolver novos } \\
\text { produtos a partir } \\
\text { do material } \\
\text { reciclado. }\end{array}$ & $\begin{array}{c}\text { Projetos e } \\
\text { protótipos de } \\
\text { novos produtos }\end{array}$ & $\begin{array}{c}\text { Projetos } \\
\text { Acadêmicos }\end{array}$ & EJr Midas \\
\hline
\end{tabular}




\begin{tabular}{|c|c|c|c|c|c|c|}
\hline $\begin{array}{c}18 . \\
\text { Formalização } \\
\text { das iniciativas } \\
\text { (em } \\
\text { cooperativas, } \\
\text { associações, etc. }\end{array}$ & $\begin{array}{l}\text { Beneficiários/ } \\
\text { iniciativas }\end{array}$ & $\begin{array}{c}\text { O ISECENSA } \\
\text { assessorou a } \\
\text { comunidade na } \\
\text { criação e } \\
\text { formalização de } \\
\text { sua Associação } \\
\text { de Moradores. } \\
\text { Agora fazer } \\
\text { alinhamento. }\end{array}$ & $\begin{array}{l}\text { Alinhamento da } \\
\text { Associação de } \\
\text { Moradores da Vila } \\
\text { Tamarindo }\end{array}$ & $\begin{array}{c}\text { Ata de } \\
\text { Alinhamento da } \\
\text { Associação de } \\
\text { Moradores da Vila } \\
\text { Tamarindo }\end{array}$ & Ata & $\begin{array}{c}\text { Coordenador } \\
\text { do Projeto }\end{array}$ \\
\hline $\begin{array}{l}\text { 19. Melhoria da } \\
\text { comercialização } \\
\text { (distribuição, } \\
\text { comunicação, } \\
\text { etc.) }\end{array}$ & $\begin{array}{l}\text { Beneficiários/ } \\
\text { iniciativas }\end{array}$ & $\begin{array}{c}\text { Desenvolver os } \\
\text { canais de } \\
\text { comercialização } \\
\text { das vassouras } \\
\text { com } \\
\text { supermercados, } \\
\text { pequenos } \\
\text { comércios e até } \\
\text { residências }\end{array}$ & $\begin{array}{c}\text { Desenvolvimento } \\
\text { de folders, banners } \\
\text { e camisetas } \\
\text { Desenvolvimento } \\
\text { de website para a } \\
\text { venda dos } \\
\text { produtos }\end{array}$ & $\begin{array}{l}\text { Relatórios com o } \\
\text { número de } \\
\text { moradores } \\
\text { trabalhadores, a } \\
\text { produção mensal e } \\
\text { a renda obtida } \\
\text { com a venda das } \\
\text { vassouras }\end{array}$ & $\begin{array}{c}\text { Relatório } \\
\text { Mensal }\end{array}$ & EJr Midas \\
\hline $\begin{array}{l}\text { 20. Melhoria da } \\
\text { qualidade dos } \\
\text { produtos }\end{array}$ & $\begin{array}{l}\text { Beneficiários/ } \\
\text { iniciativas }\end{array}$ & $\begin{array}{c}\text { Serão } \\
\text { implantadas } \\
\text { melhorias da } \\
\text { qualidade no } \\
\text { processo de } \\
\text { produção, a partir } \\
\text { do treinamento } \\
\text { em Gestão da } \\
\text { Qualidade }\end{array}$ & $\begin{array}{l}\text { Desenvolvimento } \\
\text { de padrões de } \\
\text { operação para as } \\
\text { atividades da } \\
\text { produção das } \\
\text { vassouras } \\
\text { ecológicas }\end{array}$ & $\begin{array}{c}\text { Projeto de } \\
\text { Desenvolvimento } \\
\text { de padrões de } \\
\text { operação para as } \\
\text { atividades da } \\
\text { produção das } \\
\text { vassouras } \\
\text { ecológicas }\end{array}$ & $\begin{array}{c}\text { Relatório } \\
\text { Mensal }\end{array}$ & $\begin{array}{c}\text { EJr Midas e } \\
\text { professor } \\
\text { orientador }\end{array}$ \\
\hline $\begin{array}{l}\text { 21. Melhoria na } \\
\text { infra-estrutura } \\
\text { para a produção }\end{array}$ & $\begin{array}{l}\text { Beneficiários/ } \\
\text { iniciativas }\end{array}$ & $\begin{array}{c}\text { Criação de } \\
\text { projeto para } \\
\text { melhor a } \\
\text { infraestrutura da } \\
\text { fábrica. }\end{array}$ & $\begin{array}{l}\text { Reforma da casa } \\
\text { alugada para } \\
\text { abrigar a fábrica- } \\
\text { escola }\end{array}$ & $\begin{array}{c}\text { Relatório com os } \\
\text { investimentos na } \\
\text { reforma da casa }\end{array}$ & $\begin{array}{c}\text { Relatório } \\
\text { Mensal }\end{array}$ & $\begin{array}{c}\text { Coordenador } \\
\text { do Projeto }\end{array}$ \\
\hline $\begin{array}{l}\text { 22. Melhoria na } \\
\text { produtividade }\end{array}$ & $\begin{array}{l}\text { Beneficiários/ } \\
\text { iniciativas }\end{array}$ & $\begin{array}{c}\text { Serão } \\
\text { aperfeiçoadas } \\
\text { melhorias na } \\
\text { produção no } \\
\text { processo de } \\
\text { produção, a partir } \\
\text { do treinamento } \\
\text { em Gerência da } \\
\text { Produção e } \\
\text { Planejamento e } \\
\text { Controle da } \\
\text { Produção (PCP) }\end{array}$ & $\begin{array}{c}\text { Implementação de } \\
\text { técnicas de } \\
\text { Gerência da } \\
\text { Produção e PCP }\end{array}$ & $\begin{array}{c}\text { Projeto de } \\
\text { Implementação de } \\
\text { técnicas de } \\
\text { Gerência da } \\
\text { Produção e PCP }\end{array}$ & $\begin{array}{l}\text { Relatório } \\
\text { Trimestral }\end{array}$ & $\begin{array}{c}\text { EJr Midas e } \\
\text { professor } \\
\text { orientador }\end{array}$ \\
\hline
\end{tabular}

\section{Indicadores Ambientais}

\begin{tabular}{|c|c|c|c|c|c|c|}
\hline $\begin{array}{c}\text { Indicadores do } \\
\text { PRÊEMIO }\end{array}$ & Público (1) & $\begin{array}{c}\text { Objetivos } \\
\text { Específicos do } \\
\text { projeto (2) }\end{array}$ & $\begin{array}{c}\text { Ações do projeto } \\
\text { (3) }\end{array}$ & $\begin{array}{c}\text { Fontes de } \\
\text { Informação (4) }\end{array}$ & $\begin{array}{c}\text { Meios de } \\
\text { verificação } \\
\text { (5) }\end{array}$ & $\begin{array}{c}\text { Responsáve } \\
\text { is (6) }\end{array}$ \\
\hline $\begin{array}{l}\text { 23. Ampliação } \\
\text { da consciência } \\
\text { socioambiental }\end{array}$ & $\begin{array}{l}\text { Beneficiários/ } \\
\text { comunidade }\end{array}$ & $\begin{array}{l}\text { Continuará sendo } \\
\text { desenvolvido } \\
\text { esforços para a } \\
\text { conscientização } \\
\text { socioambiental de } \\
\text { estudantes e } \\
\text { moradores, a partir } \\
\text { do treinamento em } \\
\text { Gestão da } \\
\text { Ambiental }\end{array}$ & $\begin{array}{l}\text { Implementação de } \\
\text { técnicas de } \\
\text { gerenciamento de } \\
\text { resíduos sólidos }\end{array}$ & $\begin{array}{l}\text { Projeto de } \\
\text { Implementação de } \\
\text { técnicas de } \\
\text { gerenciamento de } \\
\text { resíduos sólidos }\end{array}$ & $\begin{array}{l}\text { Relatório } \\
\text { Trimestral }\end{array}$ & $\begin{array}{c}\text { EJr Midas e } \\
\text { professor } \\
\text { orientador }\end{array}$ \\
\hline
\end{tabular}




\section{CONSIDERAÇÕES FINAIS}

O objetivo deste estudo foi a criação de um novo modelo de gerenciamento da cadeia de suprimentos da Fábrica ecológica da comunidade Tamarindo onde a elaboração do modelo de aquisição de suprimentos utilizados na fabricação das vassouras ecológicas; desenvolvimento de um planejamento de produção; melhoramento dos indicadores e a criação de novas bases para o produto fim juntamente com a melhoria da Segurança foram marcos da pesquisa.

Espera-se que a pesquisa continue agregando novos processos e valores e ocorra uma sinergia entre a aplicação prática de conceitos aprendidos nos cursos de Engenharia de produção e Administração do ISECENSA para uma melhoria na produtividade da Fábrica de Vassouras ecológicas Tamarindo em função de uma melhoria operacional e estratégica, gerando grandes resultados para toda a cadeia de suprimentos da empresa.

Problemática como a formação do preço desta nova vassoura elaborada a partir de um levantamento de todos os custos e despesas relacionadas a fábrica e um setor comercial ainda com problemas onde temas como marketing e vendas precisam ser estudadas para o crescimento da marca e de novos clientes.

\section{REFERÊNCIAS}

BALLOU, R. H. Gerenciamento da cadeia de suprimentos/logística empresarial. 5.ed. Porto Alegre: Bookman, 2006.

CARVALHO, Marcius Fabius. Importância da Informação no Desempenho da Cadeia de Suprimentos - Um estudo Exploratório. In: Simposio de Engenharia de Produção-UNESP, 2005.

CHOPRA, Sunil; MEINDL, Peter. Gerenciamento da cadeia de suprimentos. Estratégia, planejamento e operações. Ed. Peasson/ Pentice Hall. São Paulo. 2004

GIL, A.C. Como Elaborar Projetos de Pesquisa. 4a ed. São Paulo: Editora Atlas AS, 2005.

MARTINS, P. G; LOUGENI, F. P. Administração de produção. São Paulo: Editora Saraiva, 2002.

POIRIER, C. C.; REITER, S. E. Otimizando sua rede de negócios. São Paulo: Futura, 1997.

PRINGLE, B; BARKER, M. Starting a waste plastics recycling business. 2000. Disponível em: Acesso em: 15/08/2016. 